\title{
MODEL PENULISAN BUKU AJAR BIOLOGI SMA BERWAWASAN EKOLOGI DAN LOKAL UNTUK MENINGKATKAN KEPEDULIAN SISWA TERHADAP LINGKUNGAN
}

\author{
Achyani $^{1)}$ \\ Nuryani Y. Rustaman dan Sri Redjeki ${ }^{2)}$ \\ Devi Nandita Choesin ${ }^{3)}$ \\ 1) Pendidikan Biologi FKIP Universitas Muhammadiyah Metro, \\ 2) Universitas Pendidikan Indonesia, 3) Institute Teknologi Bandung
}

\begin{abstract}
A study using Research and Development design was conducted to produce a model of Biology hand book writing which is ecology and local oriented as an effort to increase students' care toward environment. The background of this research is the reality which is still going on untill now that the awareness and care of the school graduatee toward the environement safety is still low. Besides, hard science instructional at school could not affect or intervene the graduatee's characteristics, for instance in keeping the environment awareness. Meanwhile, there are many concepts of environment which had been taught through hard science especially biology, so in the researcher's point of view, biology subject has strategic role to prevent or mitigate the environment disaster caused by human activities. The model was validated at beach ecosystem. The analysis of the research result includes three aspects, namely: 1) text comprehension, 2) environment care attitude, and 3) handbook readibility. Based on the result of beach ecosystem data analysis, it was found that (1) there was a significant difference between experimental class and control class in the beach ecosystem which is shown by $t_{\text {calculation }}>t_{\text {table }}$ (7.429 > 2.00); (2) there was strong correlation between students' comprehension and attitude which is shown by coeficient correlation (r) 0.634. While the text readability test (Cloze test) shown the readability of beach ecosystem text is $\mathbf{5 7 , 5 7 \%}$ (moderate). Therefore, it can be concluded that all of the texts in the developed book are fit and proper for SMA students of grade X.
\end{abstract}

Kata kunci: Penulisan buku ajar, orientasi ekologi dan lokal, kepedulian terhadap lingkungan.

Proses pendidikan yang berlangsung di sekolah sudah seharusnya mengakomodasi realitas di sekitar siswa, bahkan, mencari jawaban atas realitas itu. Pendidikan adalah sistem yang terus berubah yang sejalan dengan sifat dari realitas dan tujuan sekolah bukan hanya untuk menghafal teori-teori saja, tetapi untuk berteori sesuai perubahan realitas.
Oleh karena itu, sebagai sebuah proses perubahan, pendidikan harus membangun pemikiran siswa yang dinamis dan terbuka sejalan dengan realitas di sekitar siswa yang selalu berubah

Pemberlakuan Kurikulum Tingkat Satuan Pendidikan (KTSP) telah memberikan dorongan bagi 
terwujudnya desentralisai pendidikan, khususnya dalam aspek kurikulum. KTSP memberikan rambu-rambu ke arah perlunya pengkajian terhadap strategi pembelajaran yang akrab dengan realitas sekitar siswa. Dalam hal ini peran guru sangat menentukan bagi keberhasilan implementasi KTSP di lapangan. Guru dituntut untuk dapat memahami gerak perubahan dari realitas yang ada di sekitar siswa.

Pengembangan suatu model buku ajar khususnya yang mengkaji permasalahan lingkungan sekitar siswa, hendaknya sesuai dengan keadaan daerah yang bersangkutan dengan tetap memperhatikan bahwa materi yang dikembangkan harus disesuaikan dengan perkembangan siswa, kemampuan, minat dan kebutuhannya. Sejalan dengan itu, maka pengembangan materi buku ajar biologi yang berorientasi pendidikan lingkungan hidup harus mengacu pada karakteristik daerah yang bersangkutan, baik berkenaan dengan kondisi bentang alam, sumber daya alam, maupun budaya masyarakat dalam berinteraksi dengan lingkungan sekitarnya. Masalahmasalah berkenaan dengan itu semua dikaji dalam perspektif ekologi.

Kondisi lain yang mendukung pentingnya buku ajar yang relevan dengan kebutuhan siswa adalah kenyataan bahwa adanya perbedaan proses-proses ekologi yang terjadi pada bentang alam yang berbeda. Sebagai contoh, jaring-jaring kehidupan yang berlangsung di ekosistem persawahan berbeda dalam hal jenis dan jumlah organisme yang terlibat dengan yang terjadi di ekosistem pantai. Buku ajar yang digunakan seringkali tidak mempertimbangkan hal tersebut. Akibatnya siswa yang berada di ekosistem pantai secara "terpaksa" hanya mempelajari jaring-jaring makanan yang terjadi di ekosistem pertanian dan daratan, sehingga tidak pernah mengetahui bagaimana sebenarnya jaring-jaring makanan yang berlangsung di pantai dan laut.

Disisi lain, adanya kenyataan yang berlangsung hingga saat ini bahwa dampak "pendidikan lingkungan" berupa kesadaran dan kepedulian lulusan sekolah terhadap keselamatan lingkungan masih rendah. Sering muncul pertanyaan menggugat di masyarakat, mengapa pendidikan IPA di sekolah tidak bisa mempengaruhi atau mengintervensi watak lulusannya, misalnya dalam kesadaran menjaga lingkungan hidupnya? Padahal konsepkonsep lingkungan banyak diajarkan dalam mata pelajaran IPA khususnya biologi. Penulis sependapat, pelajaran biologi memiliki peran strategis untuk mencegah atau setidaknya menekan (mitigasi) bencana lingkungan yang disebabkan oleh ulah manusia.

Dalam Peraturan Menteri Pendidikan Nasional Republik Indonesia Nomor 11 Tahun 2005 pasal 2 tentang Buku Ajar Pelajaran disebutkan 2 (dua) jenis buku ajar pelajaran sebagai berikut: (1) buku ajar pelajaran yang digunakan sebagai acuan wajib oleh guru dan peserta didik dalam proses pembelajaran; (2) buku pengayaan dan buku referensi yang berfungsi untuk menambah pengetahuan dan wawasan peserta didik (Depdiknas, 2005).

Buku ajar memiliki dua misi utama, yaitu buku ajar harus dapat menjadi sumber ilmu pengetahuan dan menjadi media yang baik dan dapat membantu mengoptimalkan proses pembelajaran. Telah disadari oleh para penulis bahwa buku ajar perlu mengacu pada tuntutan kurikulum. Kurikulum itu tidak hanya menuntut para siswa SMA lulus Ujian Nasional dengan nilai baik, melainkan lebih dari itu diharapkan siswa dapat menggunakan hasil belajar biologi untuk memecahkan masalah sehari-hari. Belajar biologi diharapkan bermanfaat bagi siswa untuk 
meningkatkan kualitas manusia dan lingkungan, karena belajar biologi berarti berupaya untuk mengenali proses kehidupan nyata di lingkungannya.

Wawasan ekologi yang dimaksudkan disini adalah pandangan atau cara pandang sesuatu menggunakan prinsip berpikir ekologi. Buku ajar berwawasan ekologi merupakan buku ajar yang berisi konsep-konsep biologi yang telah diperkaya oleh prinsip berpikir ekologi. Prinsip ekologi yang dimaksud meliputi: keintegralan, keseimbangan, kesinambungan, dan keragaman. Maisng-masing prinsip ekologi tersebut diuraikan kedalam indikator prinsip dan dari indikator prinsip dikembangkan menjadi berpikir ekologi. Masing-masing konsep biologi, dalam penelitian ini konsep-konsep ekosistem, setidaknya diperkaya oleh satu prinsip ekologi.

Pemberlakuan

Kurikulum

Tingkat Satuan Pendidikan (KTSP) telah memberikan dorongan bagi terwujudnya desentralisai pendidikan, khusunya dalam aspek kurikulum. KTSP memberikan rambu-rambu ke arah perlunya pengkajian terhadap strategi pembelajaran yang akrab dengan realitas sekitar siswa. Dalam hal ini peran buku ajar yang mengkaitkan realitas lokal akan sangat membantu keberhasilan implementasi KTSP di lapangan.

Materi (content) lokal bersumber dari semua kondisi dan kehidupan nyata serta fenomena yang ada di lingkungan sekitar siswa yang disusun secara sistematis yang di dalamnya termasuk lingkungan fisik, sosial, pemahaman, keyakinan, dan wawasan lokal peserta didik. Materi lokal yang dikembangkan disesuaikan dengan standar kompetensi dan silabus ekosistem sesuai kurikulum KTSP. Dari semua hal tersebut, dalam penulisan buku ajar biologi yang perlu mendapat penekanan yaitu lingkungan fisik, pemahaman, dan wawasan lokal peserta didik. Lingkungan sekitar siswa yang dimaksudkan dalam penelitian ini adalah ekosistem persawahan

Ketersediaan buku ajar biologi yang berwawasan ekologi dan lokal yang bertujuan meningkatkan kepedulian siswa terhadap lingkungan hidup masih sangat kurang. Kekurangan buku ajar tersebut sebenarnya bisa diatasi bila guru memilki keterampilan menulis buku ajar dan mau melepaskan ketergantungan yang begitu besar terhadap penerbit buku. Bahkan buku yang disusun langsung oleh guru bisa lebih sesuai dengan standar kompetensi dan kompetensi dasar siswa serta lingkungan sekitar siswa. Permasalahannya terletak pada adanya keterbatasan pengetahuan dan keterampilan menulis buku ajar yang dimiliki guru.

Di sisi lain, pengetahuan para guru terhadap pendidikan lingkungan hidup belum memadai. Terdapat sejumlah permasalahan untuk dipecahkan, antara lain: (1) masih kurangnya tenaga guru yang terdidik dalam pendidikan lingkungan hidup; (2) guru yang telah mendapat pelatihan belum seluruhnya memiliki keterampilan yang memadai untuk mengajarkan pendidikan lingkungan hidup yang terintegrasi pada bidang pelajaran masing-masing di kelas; (3) materi lingkungan hidup terdapat dalam berbagai mata pelajaran pada jenjang pendidikan dasar dan menengah, namun keberadaannya seringkali tidak disadari oleh guru sebagai sebuah kajian yang harus diajarkan sebagai pendidikan lingkungan hidup sehingga materi tersebut tidak mendapat penekanan sebagai kajian yang ditujukan untuk membangun kesadaran dan wawasan lingkungan hidup siswa (Dikdasmen, 2001). Sebagai salah satu upaya mengatasi permasalahan di atas kiranya perlu dikembangkan model penulisan buku ajar biologi SMA yang 
berwawasan ekologi dan lokal sebagai upaya meningkatkan kepedulian siswa terhadap lingkungan sekitar.

Rumusan masalah yang diajukan dalam penelitian ini adalah: Bagaimanakah model penulisan buku ajar biologi SMA berwawasan ekologi dan lokal yang dapat meningkatkan pemahaman dan kepedulian siswa terhadap lingkungan sekitar? Secara khusus permasalahan yang menjadi objek dalam penelitian adalah sebagai berikut.

a. Realitas lokal apakah yang perlu dan relevan diintergrasikan ke dalam pokok bahasan ekosistem pantai yang dapat meningkatkan pemahaman dan kepedulian siswa terhadap lingkungan sekitar.

b. Bagaimanakah strategi pengembangan model penulisan buku ajar biologi SMA berbasis ekologi dan lokal yang dapat meningkatkan pemahaman dan kepedulian siswa terhadap lingkungan sekitar.

c. Apakah model penulisan buku ajar biologi SMA yang berbasis ekologi dan lokal cukukp efektif untuk meningkatkan pemahaman dan kepedulian siswa terhadap lingkungan sekitar.

Penelitian ini bertujuan untuk memperoleh gambaran empirik tentang:

a. Realitas lokal yang diperlukan dan relevan untuk dintergrasikan ke dalam pokok bahasan ekosistem persawahan dan pantai yang dapat meningkatkan pemahaman dan kepedulian siswa terhadap lingkungan sekitar.

b. Mendapatkan strategi pengembangan model penulisan buku ajar biologi SMA berbasis ekologi dan lokal yang dapat meningkatkan pemahaman dan kepedulian siswa terhadap lingkungan sekitar.

c. Efektivitas model penulisan buku ajar biologi SMA yang berbasis ekologi dan lokal untuk meningkatkan pemahaman dan kepedulian siswa terhadap lingkungan sekitar.

\section{METODE}

Desain penelitian yang digunakan mengacu pada Research and Development dari Borg \& Gall (1983). Desain tersebut meliputi empat tahap, yaitu: 1) studi pendahuluan; 2) perencanaan program; 3) pengembangan program; 4) validasi dan revisi program.

a. Studi pendahuluan merupakan kegiatan awal penelitian yang terdiri dari studi kepustakaan dan survei lapangan untuk mengidentifikasi materi lokal yang relevan.

b. Pada perencanaan program dilakukan penentuan aktivitasaktivitas yang harus dilakukan sehubungan dengan penyusunan model konseptual, pedoman wawancara, dan angket.

c. Pada tahap pengembangan program dilakukan penilaian terhadap draft program, revisi draft program berdasarkan hasil penelitian, ujicoba program yang telah direvisi, dan revisi berdasarkan hasil ujicoba program. Penilaian terhadap draft program dilakukan berdasarkan konsultasi dengan pakar perbukuan.

d. Validasi dan revisi program dalam rangka memperoleh panduan buku ajar yang final sehingga perlu diuji kembali ketepatannya melalui validasi. Hasil dari proses validasi model diperoleh produk panduan buku ajar akhir yang siap dideseminasikan.

\section{HASIL}

Hasil penelitian ini diuraikan dalam empat bagian yang disusun berdasarkan tahapan penelitian seperti berikut: 
Identifikasi Materi yang Bermuatan Lokal

Materi (content) lokal bersumber dari semua kondisi dan kehidupan nyata serta fenomena yang ada di lingkungan sekitar siswa yang disusun secara sistematis yang di dalamnya termasuk lingkungan fisik, sosial, pemahaman, keyakinan, dan wawasan lokal peserta didik. Dalam hal ini yang dimaksud lingkungan sekitar siswa adalah ekosistem pantai. Untuk mengungkap materi bermuatan lokal tersebut digunakan lembar pengamatan siswa terhadap permasalahan lokal. Lembar pengamatan siswa berisi tiga hal pokok yaitu: (1) identifikasi jaring kehidupan di ekosistem pantai; (2) permasalahan lingkungan di eksosistem pantai; (3) kearifan lokal yang masih dipraktikkan oleh nelayan sampai saat ini, (4) dampak berantai (sirkuler) kegiatan manusia yang tidak tepat.

Adapun hasil identifikasi terhadap materi yang bermuatan lokal tersebut dipaparkan seperti berikut. Pemaparannya mengikuti fokus dalam lembar pengamatan.

\section{a. Jaring-jaring Kehidupan}

Di ekosistem pantai ditemukan 92\% siswa membuat jaring-jaring kehidupan dengan struktur yang hampir sama seperti di buku-buku teks biologi yang sebenarnya menggambarkan jaring-jaring kehidupan untuk di daerah pertanian atau hutan dan bukan di ekosistem pantai. Sisanya (8\%) membuat jaring kehidupan di laut meskipun tidak lengkap.

b. Hasil Identifikasi permasalahan lingkungan lokal

Di ekosistem pantai, secara substansi permasalahan di ekosistem pantai dapat dikelompokkan menjadi: (1) dampak kerusakan hutan mangrove;

(2) dampak budidaya tambak udang;

(3) pencemaran pantai. c. Kearifan Lokal yang masih dipraktikkan nelayan

Kearifan lokal di ekosistem pantai: (1) tidak menangkap ikan muda; (2) tidak membuang sampah ke laut; (2) tidak membunuh ikan yang terdampar.

d. Kegiatan yang menimbulkan dampak sirkuler

Dampak berantai di ekosistem pantai: (1) hutan mangrove rusak menyebabkan ikan kehilangan tempat bertelur dan membesarkan ikan, sehingga ikan di laut menjadi langka dan kehidupan nelayan menjadi susah karena penghasilannya menurun; (b) bekas tambak udang menjadi sarang dan bertempat bertelur nyamuk sehingga mengganggu kesehatan warga sekitar.

\section{Keterbacaan Buku Ajar}

Secara keseluruhan buku ajar di ujikan terhadap 300 siswa SMA kelas X di wilayah Lampung Timur. Hasil uji keterbacaan wacana buku ajar yang dikembangkan secara teknik Cloze (Sadtono, 1979) yang dimodifikasi dengan menganalisis jawaban pada tiap kata yang dilesatkan dengan tujuan agar dapat mengganti kata yang mendapatkan skor rendah dengan kata yang lebih tepat. Adapaun hasil uji keterbacaan tersebut menunjukkan tingkat keterbacaan masing-masing wacana sebagai berikut: kategori keterbacaan wacana Ekosistem Pantai: 57, 57\% (sedang). Dengan demikian, seluruh naskah wacana bahan ajar yang dikembangkan tersebut memenuhi syarat dan layak digunakan oleh siswa SMA kelas X.

\section{Hasil Penilaian Pengguna dan Ahli}

Hasil penilaian kelayakan naskah model bahan ajar yang dilakukan oleh praktisi (guru), dua orang guru berasal dari SMA yang 
berada di lingkungan pantai. Dari dua orang guru yang diminta untuk menilai tersebut kesemuanya menyatakan naskah bahan ajar baik pada pokok bahasan Ekosistem Pertanian maupun Ekosistem Pantai layak dan baik untuk digunakan oleh siswa SMA kelas X. Skor penilaian selengkapnya dari empat orang guru yang menilai tersebut adalah:

Hasil validasi ahli (expert) dapat dipaparkan sebagai berikut. Berdasarkan penilaian ahli, materi ekosistem pantai layak untuk digunakan. Terdapat lima saran penting dari ahli tersebut: (1) masih terdapat kalimat yang terlalu panjang yang menyulitkan siswa untuk memahaminya; (2) hasil penugasan kepada siswa agar benar-benar dilaksanakan dengan baik karena efek yang akan diperoleh dari penugasan tersebut dapat menimbulkan empati dan tanggungjawab siswa terhadap lingkungannya; (3) agar pada setiap komponen abiotik diberi muatan ekologis lebih mendalam; (4) untuk teks ekosistem pantai ditambahkan aktivitas penduduk yang menjadi penyebab punahnya hutan mangrove di Labuan Maringgai selain pertambakan.

\section{Hasil Penerapan Model}

a. Hasil Uji Perbandingan Buku Ajar Ekosistem Pertanian

Pengujian terhadap capaian skor

hasil belajar dilakukan dengan membandingkan hasil belajar biologi SMA kelas $\mathrm{X}$ yang pembelajarannya menggunakan model buku ajar berwawasan ekologi dan berbasis lokal dengan yang konvensional pada pokok bahasan ekosistem pantai. Hasil belajar yang bandingkan merupakan skor perolehean (gain) siswa berdasarkan selisih dari pretest dan postest yang telah dinormalisasikan (normalized gain).

Hasil analisis dan interpretasi data hasil pembelajaran menggunakan model buku ajar berwawasan ekologi dan berbasis lokal dengan yang konvensional pada pokok bahasan ekosistem pantai seperti terlihat pada Tabel 1.

Berdasarkan tahapan dan kriteria di atas, didapatkan nilai $\mathrm{t}$ hitung > t tabel $(6,150>2,00)$ dan signifikansi $<0,05(0,00<0,05)$, maka Ho ditolak. Kesimpulan: ada perbedaan antara rata-rata nilai tes kelompok siswa yang pembelajarannya menggunakann model penulisan buku ajar berwawasan ekologi dan lokal dengan kelompok siswa yang menggunakan pembelajaran konvensional (non perlakuan) pada materi ekosistem pantai.

Untuk mengetahui kekuatan hubungan antara pengetahuan dan kepedulian siswa terhadap lingkungan pantai maka dilakukan uji korelasi Pearson. Hasil uji korelasi Pearson terlihat pada Tabel 2.

Dari Tabel 2 terlihat signifikansi lebih kecil dari 0,05 maka Ho ditolak dan dapat diartikan bahwa ada hubungan antara pengetahuan dan sikap siswa dalam materi Ekosistem Pantai pada kelompok perlakuan. Kekuatan korelasinya sebagaimana terlihat dalam tabel hasil analisis data, korelasi antara pengetahuan dan sikap memberikan nilai koefisien (r) sebesar 0,634. Koefisien korelasi r 0,60-0,799 maka dapat diartikan bahwa: Hubungan antara sikap dan pengetahuan siswa pada materi ekosistem pantai untuk kelompok perlakuan kuat. Angka positif menunjukkan hubungan positif, yaitu jika pengetahuan meningkat maka sikap meningkat pula. Salah satu penyebab utama dari kuatnya hubungan tersebut adalah pemahaman siswa terhadap kelestarian ekosistem pantai yang didapat dari pembelajaran yang menggunakan buku model. 
Tabel 1 Hasil Uji Independen Sample T-Test

\begin{tabular}{|c|c|c|c|c|c|}
\cline { 3 - 6 } \multicolumn{2}{c|}{} & F & Sig. & t & Sig. (2-tailed) \\
\hline $\begin{array}{c}\text { SKOR } \\
\text { Treat vs non } \\
\text { Treat }\end{array}$ & Equal variances assumed & $.136 * *$ & $.288 * *$ & $7,429 * *$ & $.000 * *$ \\
\cline { 2 - 6 } & Equal variances not assumed & & & 7,429 & .000 \\
\hline
\end{tabular}

Ket. ** Signifikan pada $\alpha=0,05$

Tabel 2 Hasil Analisis Data Korelasi Pearson aAntara Pengetahuan dan Sikap Siswa pada Materi Ekosistem Pantai

\begin{tabular}{|c|c|c|c|}
\hline \multicolumn{2}{|c|}{} & Pengetahuan & Sikap \\
\hline \multirow{3}{*}{ Pengetahuan } & Pearson Correlation & 1 & $.634^{* *}$ \\
\cline { 2 - 4 } & Sig. (2-tailed) & & .000 \\
\cline { 2 - 4 } & $\mathrm{N}$ & 80 & 80 \\
\hline \multirow{2}{*}{ Sikap } & Pearson Correlation & $.634^{* *}$ & 1 \\
\cline { 2 - 4 } & Sig. (2-tailed) & .000 & \\
\cline { 2 - 4 } & $\mathrm{N}$ & 80 & 80 \\
\hline
\end{tabular}

**. Correlation is significant at the 0.01 level (2-tailed).

\section{KESIMPULAN}

1. Penggunaan ekologi dalam biologi dapat pengintegrasian yang berasal dari realitas lokal ke dalam konsep-konsep biologi.

2. Penggunaan buku ajar berwawasan ekologi dan lokal memberikan pengaruh terhadap peningkatan hasil belajar siswa pada materi ekosistem persawahan.

3. Terdapat hubungan yang kuat antara pemahaman dan sikap siswa yang pembelajarannya menggunakan buku ajar berwawasan ekologi dan lokal pada materi ekosistem persawahan.

\section{DAFTAR RUJUKAN}

Departemen Pendidikan Nasional. (2003). Standar Penilaian Buku Pelajaran Sains. [Online]. Tersedia: http://www. sibi.ca.id. [20 Maret 2006].
Ditjen Pendidikan Dasar dan Menengah. (2001). Pedoman Pembinaan Pendidikan Kependudukan dan Lingkungan Hidup di Sekolah. Jakarta: Dikdasmen.

(2005). Panduan Pelatihan untuk Pelatih II Pendidikan Lingkungan Hidup. Sawangan: DepdinasWJEMP pusat.

EETAP Resource Library. (2004). How Environmental Education is Used in Schools. [online]. Tersedia:http://www.eetap.org/htm 1/online_ee_courses.php [04 April Maret 2008].

Kementrian Lingkungan Hidup (KLH) RI. (2004). Sejarah Pendidikan Lingkungan Hidup di Indonesia. [Online]. Tersedia: http://www.menlh.go.id.

November 2005].

OEA. (2002). Environmental Literacy: Scope and Sequence. [Online].

Tersedia:

http://www.moea.state.mn.us/publi 
cations/ScopeandSequence02.pdf.

[20 November 2005].

Ramli, Z. (1999). "SETS dalam Buku Ajar". Makalah. Kerjasama SEAMEO-RESCAM-

DEPDIKNAS, Jakarta.

Rustaman, A. dan Rustaman, N. (2001). Petunjuk Penulisan Buku Pelajaran Biologi SLTP. Jakarta: Pusbuk-Depdiknas.

Stapp, W.B. (1974). An Instructional Program Approach to Environmental Education (K-12). In Swan. J.A \& Stapp, W.B. (ed). Environmental Education: Strategies Toward \& More Livable Future. New York: John Wiley \& Sons.

Stinner, A. (1995). Science Textbooks: Their Present Role and Future Form, in S.M. Glynn \& R. Duit. Learning Science in the Schools: Research Reforming Practice, Lawrence Erlbaum Associates Publishers.

Venkataraman, B. 2008. Why Environmental Education. [online]. Tersedia: http://www.environmentmagazin e. [20 Maret 2009]. 